\title{
Emergency peripartum hysterectomy: a 7-year review at tertiary hospital
}

\author{
Manjula S. K., Suvarchala Katakam*, Shobha G.
}

Department of Obstetrics and Gynecology, St. Johns Medical College and Hospital, Bengaluru, Karnataka, India

Received: 02 June 2019

Accepted: 07 August 2019

\section{*Correspondence:}

Dr. Suvarchala Katakam,

E-mail: suvarchalakatakam@gmail.com

Copyright: (c) the author(s), publisher and licensee Medip Academy. This is an open-access article distributed under the terms of the Creative Commons Attribution Non-Commercial License, which permits unrestricted non-commercial use, distribution, and reproduction in any medium, provided the original work is properly cited.

\begin{abstract}
Emergency peripartum hysterectomy (EPH) is a major obstetric procedure, usually performed as a life-saving measure in cases of intractable obstetric hemorrhage. The aim of this study was to determine the incidence, indications and the risk factors and complications of emergency peripartum hysterectomy (EPH). The medical records of 13 patients who had undergone EPH, between January 2012 and December 2018, were reviewed retrospectively. All necessary data was obtained by record review. The mean age of pregnant women was 30 year. There were 13 EPHs out of 15768 deliveries, a rate of 0.82 per 1,000 deliveries. Out of 13 women who underwent EPHs, 8 hysterectomies were performed after cesarean delivery and 5 after vaginal delivery. The most common indication for hysterectomy was abnormal placentation (7/13), followed by atony (4/13), rupture of scared uterus (1/13) and rupture of unscared uterus (1/13). There were two cases of intra-operative bladder injury, we had 1/13 maternal death because of EPH. There were no cases of neonatal mortality. In our series, abnormal placentation was the most common of indication for EPH. The risk factors for EPH were previous CS for abnormal placentation and placental abruption for uterine atony and peripartum hemorrhage. Limiting the number of CS deliveries would bring a significant impact on decreasing the risk of EPH.
\end{abstract}

Keywords: Emergency, Peripartum, Hysterectomy

\section{INTRODUCTION}

Emergency peripartum hysterectomy (EPH) is a major obstetric procedure, usually performed as a life-saving measure in cases of intractable obstetric hemorrhage. ${ }^{1-3}$ Emergency peripartum hysterectomy $(\mathrm{EPH})$ is associated with significant morbidity and mortality worldwide. They are seen more often in developing countries due to decreased availability and lack of uptake of antenatal care services especially in the rural areas. There also appears to be a rise of EPH in the developing world as well. ${ }^{1}$ Recent studies have indicated that abnormal placentation is replacing uterine atony as the most common indication for $\mathrm{EPH}^{4}{ }^{4}$ The overall incidence of EPH is $0.05 \%$, but there are considerable differences in incidence in different parts of the world, depending on modern obstetric services, standards and awareness of antenatal care, and the effectiveness of family planning activities of a given community. ${ }^{5}$ The incidence of peripartum hysterectomy in the literature is reported as $0.24,0.77$, 2.3, and 5.09 per 1,000 deliveries by Sakse et al, Whiteman et al, Bai et al, and Zeteroglu et al, respectively. ${ }^{6-9}$

Severe postpartum hemorrhage was reported to occur in $6.7 / 1,000$ deliveries worldwide. It is one of the leading 
causes of maternal mortality and morbidity and represents the most challenging complication that an obstetrician will face. ${ }^{10}$ The main causes of the uncontrollable hemorrhage necessitating an EPH have changed since the $1980 \mathrm{~s}^{2}{ }^{2}$ Uterine atony and rupture have been overtaken by abnormal placentation in many studies. This is not only because of improved conservative management of uterine atony and a reduced incidence of uterine rupture due to the extensive use of the lower uterine segment incision in preference to the upper uterine segment incision for cesarean section (CS), but also because of an actual increase in the incidence of the morbidly adherent placenta. Abnormal placentation, which refers to both placenta previa and the morbidly adherent placenta, is thought to be increasing because of the rising rate of CS. Studies have consistently demonstrated that previous CS increases the risk of EPH and abnormal placentation is associated with a previous uterine scar.

The purpose of our study was to review the emergency peripartum hysterectomies $(\mathrm{EPH})$ done at our institution. Our specific aim was to determine the incidence, risk factors the associated morbidity and mortality, and complications noted at our institution.

\section{METHODS}

Patients who had undergone EPH following vaginal delivery and caesarean section in a tertiary care hospital.

This was a Retrospective study. Medical records of the patients who had undergone EPH following vaginal delivery and caesarean section in between January 2012 to December 2018 in tertiary teaching hospital in Bangalore were reviewed retrospectively. Cases were ascertained via a review of hospital obstetrics database by checking the obstetric admission register, OT records, case records and mortality register. All deliveries were performed after 24 weeks of gestation. Both medical and surgical measures were used for conservative management.

Information obtained from the medical records include demographic details, risk factors, previous obstetrics history, current pregnancy and delivery detail, indication for $\mathrm{EPH}$,outcome of hysterectomy and operative and postoperative complications, maternal morbidity and mortality.

\section{Inclusion criteria}

- All the patients delivered in hospital and referred from outside presented with PPH not responding to conservative management.

\section{Exclusion criteria}

- Patients with established DIC and other co morbidities.

\section{RESULTS}

During the 7 year study period following information was gathered.

Table 1: The incidence of peripartum hysterectomy (7 year).

\begin{tabular}{|ll|}
\hline Total number of deliveries & $\mathbf{1 5 7 6 8}$ \\
\hline Total NVD & 9752 \\
\hline Total CS & 6934 \\
\hline Others & 463 \\
\hline Total EPH & 13 \\
\hline Incidence (SJMCH) & $0.82 / 1000$ deliveries \\
\hline
\end{tabular}

Table 1 shows the incidence of peripartum hysterectomy during 7 years period that is $0.82 / 1000$ deliveries.

Figure 1 shows age distribution of patients who underwent peripartum hysterectomy. The mean maternal age was 29 years. Majority of patients (6/13) were 26-30 years of age, (4/13) were in the age group of 20-25 years, $(2 / 13)$ were in the age group of $>35$ years and $(1 / 13)$ in the age of 34 year.

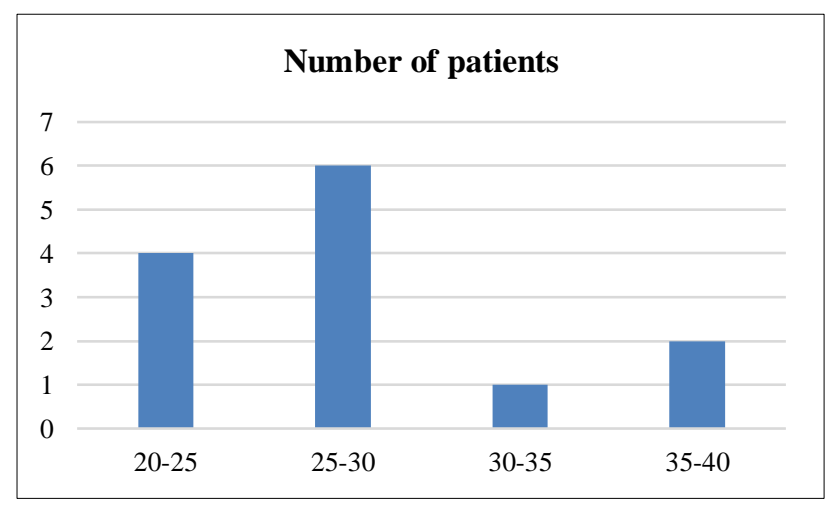

Figure 1: Age distribution of patients.

The majority of women were multi parous (9/13); of these, only one case was a grand multi parous woman (parity > 3). There were 3primiparous women (Figure 2 shows the parity of the patients who underwent peripartum hysterectomy).

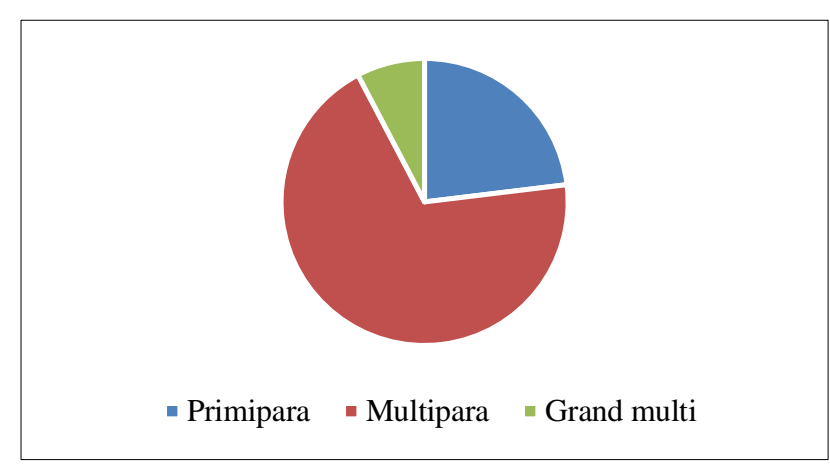

Figure 2: Parity of patients. 
Mean gestational age was 30 weeks (range 24-40+3).

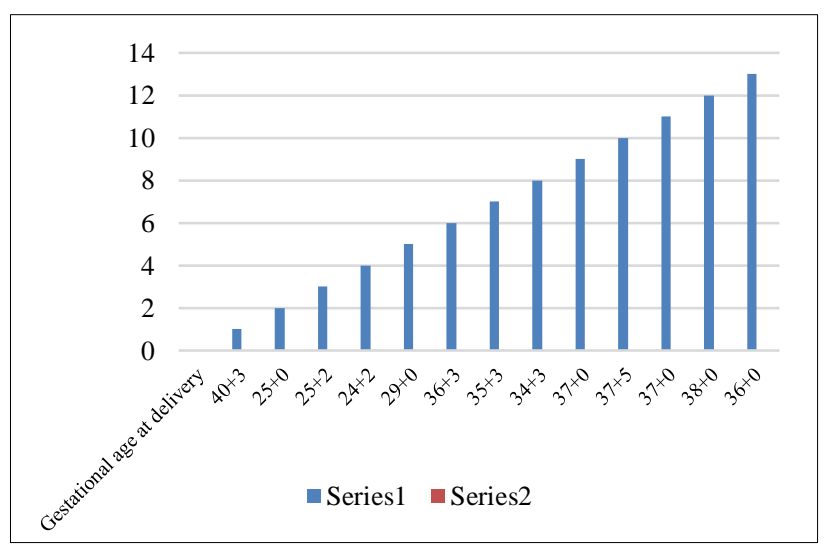

Figure 3: Gestational age at delivery.

Figure 3 denotes gestational age at delivery in patients who underwent peripartum hysterectomy.

\section{Type of delivery and its indications}

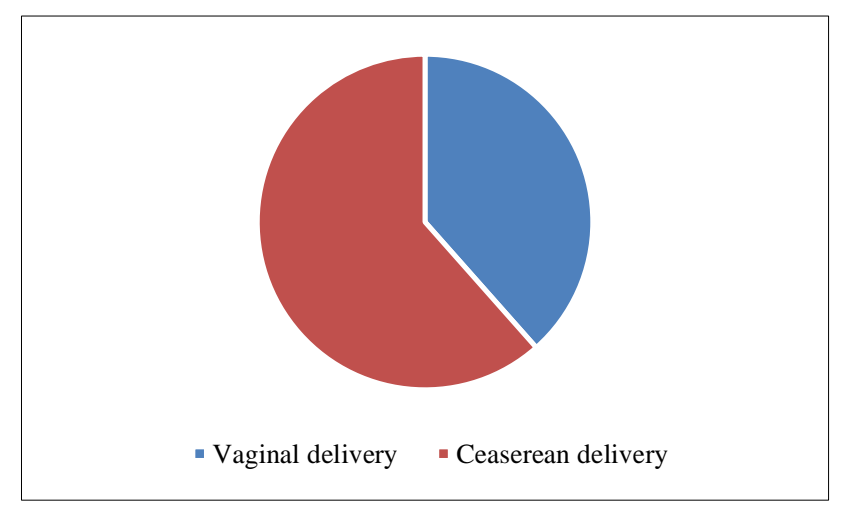

Figure 4: Mode of delivery of the patients.

In Figure 4 we present obstetric data in relation to the type of delivery. After analysing this chart, we can conclude that the majority of cases $(8 / 13)$ were cesarean delivery, followed by vaginal delivery in the others $(5 / 13)$. Of these, there were 3 cases of preterm vaginal delivery. In relation to cesarean deliveries, $2 / 8$ were elective cesareans and 6/8 were emergency cesareans. The indications for elective cesareans were placenta previa (1 case), abnormal Placentation with previous 2 caeserean section (1 case).The most frequent indication for emergency section previous ceaserean section with abnormal placentation.

Thirteen hysterectomies were performed due to intractable obstetric hemorrhage that was unresponsive to conservative management, representing an incidence of 0.82 per 1,000 deliveries $(0.082 \%)$. To avoid hysterectomy, pharmacological agents and surgical procedures were used to control hemorrhage. Indications for emergency peripartum hysterectomy are shown in Figure 5. The most common indication for EPH was placenta previa and/or accrete (7/13), followed by uterine atony (4/13), rupture scarred uterus (1/13) and rupture of unscarred uterus (1/13).

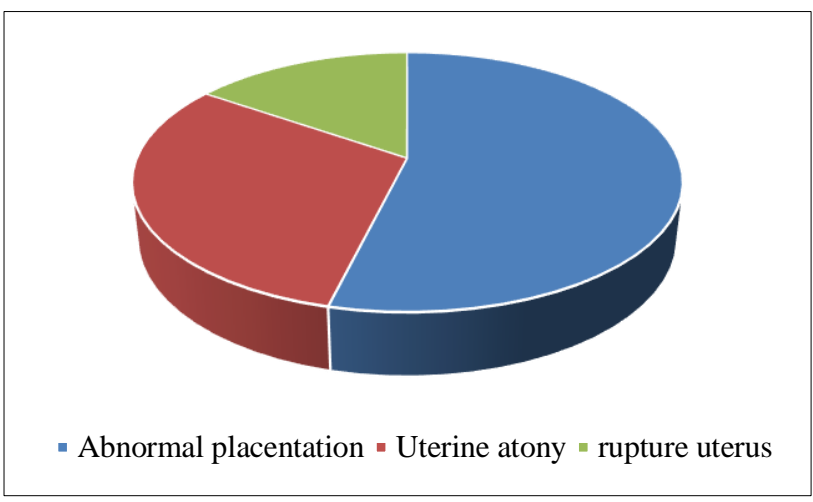

Figure 5: Indications for emergency peripartum hysterectomy.

We analysed the risk factors that predispose to EPH in our population and they are shown in Table 2 which shows that EPH is most common in multiparity cases and least common in multiple fibroids and polyhydramnios patients.

Table 2: Incidence of risk factors predisposing to EPH in our study population.

\begin{tabular}{|ll|}
\hline Risk factors & Percent $\%$ \\
\hline Placenta praevia/accreta & 53.8 \\
\hline Maternal age $>35$ & 15.3 \\
\hline Preeclampsia/Eclampsia & 15.3 \\
\hline Previous ceaserean delivery & 53.8 \\
\hline Ceaserean section & 61.5 \\
\hline Multiparity & 76.9 \\
\hline Multiple fibroid & 7.6 \\
\hline Poly hydraminos & 7.6 \\
\hline Abruptio placenta & 23 \\
\hline Anemia & 15.3 \\
\hline
\end{tabular}

In relation to cases of abnormal placentation (7/13), we can conclude that 6 of these women were multiparous women with previous LSCS. In 6 of these 7 cases, the delivery was performed by cesarean. From the analysis of this chart, we can rapidly conclude that the 7 cases of abnormal placentation 3 cases had previa, 1 of each case had accreta and increta and 2 cases had percreta, occurred in women with 30-36 years of age and with a history of cesarean section. The case of uterine rupture occurred in multiparous women with a previous cesarean delivery and in one case rupture occurred in unscarred uterus. Uterine atony occurred in 4 cases 2 cases were previous ceaserean and 2 had vaginal delivery.

The operative complications, postoperative conditions and maternal outcomes are shown in Table 3. 
Table 3: Operative complications, postoperative conditions, and maternal outcomes.

\begin{tabular}{|l|l|}
\hline Maternal complications & Number of cases \\
\hline DIC & 7 \\
\hline Injury to bladder & 3 \\
\hline Febrile illness & 2 \\
\hline Wound infection & 2 \\
\hline Intestinal obstruction & 1 \\
\hline Maternal death & 1 \\
\hline
\end{tabular}

There was three case of intra-operative bladder injury. These, patient had a previous cesarean section. All patients received blood and blood products transfusions, with the median number of units of blood transfused being 9 (range 4-35). We had 4 cases of disseminated intravascular coagulopathy that reversed with prompt management. The median postoperative hospital stay was 13 (range 6-60) days. There was one maternal death of amniotic fluid embolism had atonic PPH, this case had undergone left sided ovariotomy for mucinous cyst adenocarcinoma 18 months ago.

\section{DISCUSSION}

Despite advances in medicine and surgery, postpartum hemorrhage remains one of the leading causes of maternal morbidity and mortality. Peripartum hysterectomy is performed in the treatment of a lifethreatening obstetric hemorrhage that cannot be controlled by conventional methods. The reported incidence of emergency peripartum hysterectomy varies from 0.24 to 5.09 per 1,000 deliveries in the literature. Our incidence of 0.41 per 1,000 deliveries $(0.04 \%)$ is in agreement with the recent studies. Zeteroglu et al, reported the incidence of EPH in a teaching hospital as $5.09 / 1,000$ deliveries, which is higher than that of other studies. ${ }^{9}$

Baskett reported that the main indications for hysterectomy were abnormal placentation (50\%) and atonic postpartum hemorrhage $(32.8 \%){ }^{11}$

The febrile morbidity rate of $15.3 \%$ is higher than that of their studies. ${ }^{12-14}$

In our study, majority of patients who underwent EPH were in age group 30-36 years and were multipara. Similar trend was observed by Amad and Mir and Barclay et al. ${ }^{15,16}$ Other risk factors for EPH, like previous cesarean birth, induced labor, current cesarean delivery, and abnormal placental implantation and invasion, were similar to the literature. ${ }^{17}$

The most frequent indication for EPH in the present study was abnormal placentation, followed by morbid adherence of placenta and uterine rupture. There has been a significant change in the indication of EPH over time and from one region to another. Traditionally, uterine atony was the most common indication for hysterectomy. Recent studies have indicated that abnormal placentation is replacing uterine atony as the most common indication for EPH. In 1984, Stanco et al. reported that $43.4 \%$ of their emergency hysterectomies were done because of uterine atony, while $33.9 \%$ were due to placenta previa with accreta. A study from the same institution in 1993 stated that their primary indication was placenta accreta, the problem in $45 \%$ of cases, followed by uterine atony, with $20 \% .^{18}$ This study demonstrates that our most frequent indication for EPH abnormal placentation, followed by uterine atony, a feature that can be explained by high rate of cesarean delivery. From all this data, we can conclude that there is a considerable variability in the indications of EPH worldwide, and it varies with obstetric practice in each center.

Peripartum hysterectomy is associated with high complication rates, mainly due to the need for massive blood transfusions, coagulopathy, and injury of the urinary tract, and it is also associated with the need for reexploration because of persistent bleeding and febrile morbidity. ${ }^{2,19,20}$ All of our patients received blood transfusions and $>98 \%$ of them had over two units of blood. Bladder injury was found in 3 patients, and these patients had a previous cesarean delivery. Thus, urological injuries appear to be related to scarring and secondary adhesion of the vesicouterine space following previous cesarean section. In comparison with Smith's $6 \%$, Kwee's 15\%, Yucel's 8.8\%, Zeteroglu's 12.5\%, and Zelop's $9 \%$, our urinary tract injury rate is $23 \%$. $2,9,13,20,21$ In our series, 7 women $(53.8 \%)$ developed disseminated intravascular coagulopathy, higher than the $33 \%$ rate previously reported by Smith and Mousa and Lau et al. ${ }^{13,19}$ There was one maternal death $(7.7 \%)$ in our study. Lower rates of 4 and $4.5 \%$ were cited by Kwee et al and Zorlu et al and much higher rates of 20 and $23.8 \%$ were found by Hamshoand Alsakka and Umezurike et al.,22-24 Our low mortality rate may be related to an optimal obstetric intervention and easy availability of blood and blood products in the cases of EPH in our department. Our results confirm the previous observations that EPH is associated with high operative and postoperative complications rates.

There are numerous risk factors that can contribute for this entity and recognizing and assessing patients at risk is very important. Also, appropriate management of cases of postpartum hemorrhage is an important issue. Ideally each labor and delivery unit has a postpartum hemorrhage protocol for patients with estimated blood loss exceeding a predefined threshold (often $1000 \mathrm{~mL}$ ). These protocols provide a standardized approach to evaluating and monitoring the patient, notifying a multidisciplinary team, and treatment.

Our institute caters to both urban and rural areas in south India (Karnataka,Tamil Nadu and Andhra Pradesh). Due to inadequate health facilities, poor referral systems, inadequate transport facilities and inadequate knowledge 
about the high risk pregnancy we receive these cases in very grave condition.

\section{CONCLUSION}

In developing countries, the obstetrician will continue to encounter this unfortunate event of EPH in their day to day life but the incidence can definitely be decreased by upgrading the infrastructure, regular antenatal check up,timely referral of high risk cases, continuous upgradation of knowledge and skills, and managing these cases through various programs such as EMOC, upgrading socioeconomic status and health education.

\section{Funding: No funding sources}

Conflict of interest: None declared

Ethical approval: The study was approved by the Institutional Ethics Committee

\section{REFERENCES}

1. Rossi AC, Lee RH, Chmait RH. Emergency postpartum hysterectomy for uncontrolled postpartum bleeding: a systematic review. Obstet Gynecol. 2010;115(3):63744.

2. Kwee A, Bots ML, Visser GHA, Bruinse HW. Emergency peripartum hysterectomy: a prospective study in the Netherlands. European J Obstet Gynecol Repro Biol. 2006;124(2):187-92.

3. Akar ME, Yilmaz ES, Yuksel B, Yilmaz Z. Emergency peripartum hysterectomy. European J Obstet Gynecol Repro Biol. 2004;113(2):178-81.

4. Daskalakis G, Anastasakis E, Papantoniou N, Mesogitis S, Theodora M, Antsaklis A. Emergency obstetric hysterectomy. Acta Obstetricia Gynecol Scandinavica. 2007;86(2):223-7.

5. Park EH, Sachs BP. Postpartum haemorrhage and other problems of third stage, in high risk pregnancy management options, James DK, Steer PJ, Weiner CP, Gonik B, Eds., W.B. Saunders, Philadelphia, Pa, USA, $2^{\text {nd }}$ edition; 1999:1231-1246.

6. Sakse A, Weber T, Nickelsen C, Secher NJ. Peripartum hysterectomy in Denmark 1995-2004. Acta Obstetricia Gynecol Scandinavica. 2007;86(12):1472-5.

7. Whiteman MK, Kuklina E, Hillis SD. Incidence and determinants of peripartum hysterectomy. Obstet Gynecol, 2006;108(6):1486-92.

8. Baiv SW, Lee HJ, Cho JS, Park UW, Kim SK, Park $\mathrm{KH}$. Peripartum hysterectomy and associated factors. J Repro Med Obstet Gynecol. 2003;48(3):148-52.

9. Zeteroglu S, Ustun Y, Engin-Ustun Y, Sahin G, Kamac1 M. Peripartum hysterectomy in a teaching hospital in the eastern region of Turkey. European Journal of Obstet Gynecol Repro Biol. 2005;120(1):57-62.

10. Waterstone $M$, Bewley $S$, Wolfe $C$. Incidence and predictors of severe obstetric morbidity: case-control study. Obstet Gynecol Survey. 2002;57(3):139-40.
11. Daskalakis G, Anastasakis E, Papantoniou N, Mesogitis S, Theodora M, Antsaklis A. Emergency obstetric hysterectomy. Acta Obst Gynecol Scandinavica. 2007;86(2):223-7.

12. Selo-Ojeme DO, Bhattacharjee P, Izuwa-Njoku NF, Kadir RA. Emergency peripartum hysterectomy in a tertiary London hospital. Arch Gynecol Obstet. 2005;271(2):154-9.

13. Smith J, Mousa HA. Peripartum hysterectomy for primary postpartum haemorrhage: incidence and maternal morbidity. J Obstet Gynaecol. 2007;27(1):447.

14. Engelsen IB, Albrechtsen S, Iversen OE. Peripartum hysterectomy-incidence and maternal morbidity. Acta Obstet Gynecol Scandinavica. 2001;80(5):409-12.

15. Ahmad SN, Mir IH. Emergency peripartum hysterectomy: experience at Apex Hospital of Kashmir Valley. Internet J Gynecol Obstet. 2007;8(2).

16. Barclay DL, Hawks BL, Frueh DM, Power JD, Struble RH. Elective cesarean hysterectomy: a 5 year comparison with cesarean section. Am J Obstet Gynecol. 1976;124(8):900-11.

17. Lau WC, Fung HY, Rogers MS. Ten years experience of caesarean and postpartum hysterectomy in a teaching hospital in Hong Kong. Eu J Obstet Gynecol Reprod Biol. 1997;74(2):133-7.

18. Stanco LM, Schrimmer DB, Paul RH, Mishell DR. Emergency peripartum hysterectomy and associated risk factors. Am J Obstet Gynecol. 1993;168(3):879-83.

19. Chestnut DH, Eden RD, Gall SA, Parker RT. Peripartum hysterectomy: a review of cesarean and postpartum hysterectomy. Obst Gynecol. 1985;65(3):365-70.

20. Zelop CM, Harlow BL, Frigoletto FD, Safon LE, Saltzman DH. Emergency peripartum hysterectomy. Am J Obst Gynecol. 1993;168(5):1443-8.

21. Yucel O, Ozdemir I, Yucel N, Somunkiran A. Emergency peripartum hysterectomy: a 9-year review. Archives of gynecology and obstetrics. 2006;274(2):847.

22. Zorlu CG, Turan C, Işik A, Danişman N, Mungan T, Gökmen $\mathrm{O}$. Emergency hysterectomy in modern obstetric practice changing clinical perspective in time. Acta Obstet Gynecol Scandinavica. 1998;77(2):186-90.

23. Hamsho MA, Alsakka M. Emergency obstetric hysterectomy in Qatar: a 20-year review. Int J Fert Women's Med. 1999;44(4):209-11.

24. Umezurike CC, FEYI-WABOSO PA, Adisa CA. Peripartum hysterectomy in Aba southeastern Nigeria. Australian New Zealand J Obstet Gynaecol. 2008;48(6):580-2.

Cite this article as: Manjula SK, Katakam S, Shobha G. Emergency peripartum hysterectomy: a 7-year review at tertiary hospital. Int J Reprod Contracept Obstet Gynecol 2019;8:3812-6. 